\title{
Renal Replacement Therapy in Geriatric End-Stage Renal Disease Patients: A Clinical Approach
}

\author{
Jeroen P. Kooman Tom Cornelis Frank M. van der Sande Karel M.L. Leunissen \\ Division of Nephrology, Department of Internal Medicine, University Hospital Maastricht, \\ Maastricht, The Netherlands
}

\section{Key Words}

Renal replacement therapy · Geriatric patients $\cdot$ End-stage

renal disease

\begin{abstract}
The number of geriatric patients on dialysis is increasing. This is due to demographic factors, a wider acceptance of elderly patients on dialysis, and an earlier start of dialysis in this patient group. Recent studies have questioned the effect of dialysis on quality of life in elderly patients with severe comorbidity and showed limited survival in this specific patient group. Therefore, the decision whether or not to start dialysis may be a difficult one for both the clinician and patient. Risk scores can be of help in facilitating shared decision making, but not as a tool to withhold dialysis. However, in the elderly patient with severe comorbidity, conservative care can sometimes be a reasonable alternative to dialysis. In the process of shared decision making, a balance should be pursued between life expectancy and quality of life. If the decision to initiate dialysis is taken, choices have to be made regarding dialysis modality and treatment prescription. If adequate support is provided, assisted peritoneal dialysis can be an acceptable alternative to hemodialysis. Care for
\end{abstract}

the elderly with end-stage renal disease should be undertaken by a multidisciplinary team with special dedication to a multidimensional approach in this population.

Copyright $\odot 2012$ S. Karger AG, Basel

\section{Introduction}

The number of elderly dialysis patients is increasing. According to a recent ERA-EDTA registry report, the growth of dialysis is largely due to a higher incidence of renal replacement therapy in patients over 75 years of age [1]. In these patients, the cause of renal failure is most commonly diabetes or renal vascular disease. Treatment patterns differ widely between various countries. For instance, in Belgium, patients above 75 years comprise $41 \%$ of dialysis patients, as compared to $20 \%$ in the United Kingdom and $17 \%$ in Japan [2]. Variations in transplantation policy, timing of the start of dialysis, and survival may partly account for these differences.

The burden of dialysis may be high for geriatric patients, and the effect of dialysis on quality of life, functional status, and life expectancy may differ in the elderly as compared to younger patients. Therefore, there is

\section{KARGER}

Fax +4161306 1234 E-Mail karger@karger.ch www.karger.com
(C) 2012 S. Karger AG, Basel

0253-5068/12/0333-0171\$38.00/0

Accessible online at:

www.karger.com/bpu
Jeroen P. Kooman

Division of Nephrology, Department of Internal Medicine

University Hospital Maastricht

PO Box 5800, NL-6202 AZ Maastricht (The Netherlands)

E-Mail jeroen.kooman@mumc.nl 
ongoing discussion about the best treatment options for elderly patients with end-stage renal disease (ESRD) in the literature, in which consideration of conservative care plays an increasing role.

In this paper, recent literature regarding prognostic factors and treatment options for elderly patients (defined as patients 75 years of age or older) is reviewed.

\section{Prognosis in the Elderly Dialysis Patient}

An important factor in the decision of whether or not to start dialysis in the very elderly is the remaining life expectancy. Survival for geriatric patients on dialysis appears in general to be limited, but also varies between different reports. In a recent USRDS review, a 1-year mortality rate of $46 \%$ was observed in patients older than 80 years, which is considerably higher as compared to the general population [3]. In the REIN registry, 6-month mortality was $19 \%$ in patients 75 years or older [4]. In the DOPPS study, median survival of patients older than 75 years of age varied between 1.6 and 5.4 years in the different regions, as compared to 4.5-11.9 years in patients aged 45-74 years [2]. In a Canadian survey, mean life expectancy of patients aged 75-80 years was 3.2 years [5].

Survival after starting dialysis appears especially limited in nursing home patients. In nursing home patients with ESRD of the 2004-2006 Minimum Data Set cohort, the reported 1-year survival was $14 \%$ [6]. Surprisingly, this was lower than the 37\% reported for the cohort 1998 2000. Differences in eligibility may at least partly account for this observation, meaning that sicker patients were accepted for dialysis as compared to earlier cohorts.

In individual patients, prognosis remains difficult to predict, although several factors were found to be related to mortality in this population. In a study based on USRDS data, predictive factors were age, nonambulatory status, and number of comorbid conditions [3]. In the REIN population, a prediction model for 6-month mortality in patients 75 years or older was validated and included body mass index, diabetes, severe congestive heart failure and peripheral vascular disease, dependency for transfers, and unplanned dialysis. The 6-month mortality rate ranged from $8 \%$ in the lowest risk group to $70 \%$ in the highest risk group [4]. Notably, age was not a significant determinant for prognosis in the REIN population. However, given the remaining uncertainties at the individual level, risk scores such as those discussed above should primarily be used to facilitate discussion with patients and other stakeholders, but not to withhold dialysis
[4]. Indeed, in another model predicting mortality in high-risk patients, dialysis would have been withheld in $19 \%$ of patients who lived for more than 1 year if the model had been used to guide initiation of treatment [7]. Models based on objective data cannot be used to fully replace the expertise of professionals in the field. In one study, the so-called 'surprise question' ('Would I be surprised if this patient died within the next 6 months?') was an independent risk factor in predicting 6-month mortality in dialysis patients, next to factors such as age, peripheral vascular disease, and serum albumin [8].

\section{Trends in the Start of Dialysis}

If the elderly ESRD patient opts for dialytic ESRD care rather than for conservative ESRD care, dialysis is usually initiated at an earlier stage as compared to the younger ESRD population. In the 2010 USRDS data report, $29 \%$ of the patients 75 years of older started dialysis at a serum creatinine of $4 \mathrm{mg} / \mathrm{dl}(354 \mu \mathrm{mol} / \mathrm{l})$ or less as compared to $9 \%$ in patients between the ages of 20 and 44 [6]. More informatively, given the fact that the relation between serum creatinine and glomerular filtration rate (GFR) is strongly influenced by age in the MDRD formula, the mean estimated GFR at the start of dialysis was $12.2 \mathrm{ml} / \mathrm{min} / 1.73 \mathrm{~m}^{2}$ in patients 75 years or older as compared to $10.6 \mathrm{ml} / \mathrm{min} / 1.73 \mathrm{~m}^{2}$ in patients in the age group $45-64$. Using the MDRD formula, nearly $20 \%$ of patients aged 75 years started dialysis at an estimated GFR of 15 $\mathrm{ml} / \mathrm{min} / 1.73 \mathrm{~m}^{2}$ or higher. With the CKD-EPI equation, this percentage was $16 \%$ [6].

Moreover, the timing of the start of dialysis in the elderly appears to have shifted to higher estimated GFR values in the past decade [3]. Although an earlier start has been a general trend in dialysis therapy, this phenomenon appears to be more pronounced for the elderly population. The earlier start in elderly patients may be due to the fact that factors such as congestive heart failure or malnutrition are more prevalent in the elderly. This seems supported by recent data in nursing home residents, for whom factors such as volume overload, weight loss, increased ADL dependency, and cognitive decline were associated with earlier dialysis initiation [9]. However, these factors explained only $31 \%$ of the cases of earlier dialysis initiation. Moreover, congestive heart failure or malnutrition did not appear to be more prevalent in the 2003 cohort as compared to the 1996 cohort in the USRDS report [3]. Therefore, other factors, most likely the general tendency to start dialysis earlier, also plays a role in the 
earlier start of dialysis. Despite the trend to start dialysis earlier in the latter cohort, survival in the very elderly treated with dialysis was not notably different between 1996 and 2003. In contrast, according to the Canadian data, the mean life expectancy for dialysis patients aged 75-80 years increased from 2.7 years in the incident cohort of 1990-1994 to 3.2 years in the incident cohort of 1995-1999 [5]. Whether an earlier start leads to a survival benefit is uncertain, especially in view of the results of the IDEAL trial [10], although in this study patients older than 65 years were excluded.

\section{Effect of Dialysis on Functional Status}

Many geriatric patients suffer from frailty, a multicausal syndrome which is defined as a combination of symptoms such as weight loss, reduced gait speed, tiredness, low physical activity, and loss of muscle power [5, 11]. Additionally, in nonuremic persons the frailty syndrome is associated with a risk of death and hospitalization in excess of that expected for age. Especially in dialysis patients, frailty appears to be highly prevalent, which even holds true for younger patients. In patients below 40 years of age, $44 \%$ meet the criteria for frailty, which increases to $79 \%$ in patients above 80 years of age [12].

The prevalence of frailty is also increased in patients with chronic kidney disease (CKD) with less severe impairment of renal function [12], and holds true for cognitive impairment, which is related to the severity of renal failure [13].

The effect of starting dialysis on functional status has been the focus of recent observational studies. In patients 80 years or older, of whom $78 \%$ were independently functioning before the start of dialysis, 33\% had died after 6 months, whereas only $28 \%$ were independent (residing in own home without assistance) [14]. Especially in nursing home patients, the impact of the start of dialysis on functional status shows a worrying trend [15]. In an observational study in 37,032 incident dialysis patients from the Minimum Data Set nursing home population with a mean age of 73 years, functional status had been maintained in $39 \%$ of patients 3 months after the start of dialysis and in $13 \%$ after 1 year, whereas $58 \%$ of patients had died. Thus, by 12 months, $87 \%$ of residents had either died or experienced a decline in functional status [15].

The causal relation between the start of dialysis and decline in functional status may be difficult to elucidate from these observational data, given the fact that a decline in functional status may be one of the reasons to start dialysis [9]. The fact that the start of dialysis is associated with an unfavorable effect in the frail elderly may also be partly related to the fact that kidney failure may be a part of irreversible multiorgan dysfunction [16], in which treatment of one of the components will not have a major effect. Detailed studies on the functional trajectory in the last episode of life of conservatively treated geriatric patients with ESRD show that functional status sharply declines in the last month of life, as compared to a more gradual decline in patients with cardiac or pulmonary disease [16]. It cannot be excluded that dialysis is often started in this final trajectory due to the associated symptomatology. However, in the study of Jassal et al. [14], functional status also declined in relatively healthy elderly after the start of dialysis, possibly due to physical and psychosocial burdens related to travelling as well as the dialysis procedure itself and its accompanying interventions. Therefore, the decline in functional status after the start of dialysis is likely multifactorial. Hence, we concur with the recommendations of these authors that the start of dialysis in the elderly should be accompanied by an active rehabilitation program.

\section{Dialysis or Conservative Care?}

Given these discouraging data, the increased recent attention to conservative care in this patient group is well explained. Palliative care in ESRD has been the focus of recent reviews [17-19]. In the decision to start dialysis or opt for a conservative approach, differences in expected outcome between these two strategies are important in clinical decision making and information provision to the patient. All available data are based on observational studies and therefore subject to various forms of bias [20]. Indeed, results differ between various studies. In the study by Joly et al. [21] in patients 80 years or older, median survival was 20 months longer ( 28.9 vs. 8.9 ) in the dialysis versus the conservatively treated group. In a more recent study, the difference in survival in CKD stage 5 patients was 46 months between patients treated with dialysis and those treated with conservative care in the entire group, but less than 4 months in patients older than 75 years of age [22]. In the study by Murtagh et al. [23] in patients with CKD stage 5 over 75 years of age, 2-year survival was $76 \%$ in the group treated with dialysis and $47 \%$ in group treated with conservative therapy, which 
was significantly different. However, in patients with severe comorbidity, especially ischemic heart disease, the survival difference was less pronounced.

Another report showed a difference of 24 months in survival between patients older than 75 years treated with dialysis versus conservative care; however, this was at the expense of a nearly comparable increase in days with hospital visits (173 days per patient per year) or interventions $[24,25]$.

Thus, there is some variability in the observational data comparing conservative and dialysis therapy in the elderly. However, these data, and those derived from the prediction models discussed previously, also indicate that there are many elderly patients who may benefit from dialysis, especially those with acceptable functional status before the start of dialysis. This may be different in the elderly with severely impaired functional status and multiple comorbid diseases. Importantly, a good balance between estimated effect on survival and effect on quality of life has to be sought. Still, the outcome in individual patients may be difficult to predict.

Hence, the decision whether or not to start dialysis should be based on shared decision making with adequate provision of information by a multidisciplinary team for the patient and next of kin. According to clinical practice guidelines on shared decision making, patients should receive information on their diagnosis, prognosis, and all treatment options, including the possibility of continuing conservative management including end-life care or a time-limited trial of dialysis $[4,26,27]$. In the most recent guidelines on shared decision making from the Renal Physicians Association, it could be considered not to start dialysis in elderly CKD stage 5 patients older than 75 years who meet two or more of the following prognostic criteria: clinicians responding 'No, I would not be surprised' to the 'surprise question' (see earlier paragraph), high comorbidity score, significantly impaired functional status (e.g. Karnofsky score less than 40 ), and severe chronic malnutrition. However, given the fact that prediction scores are never absolute, in our opinion decisions made according to these guidelines should be thoroughly evaluated in future studies.

If an approach for conservative care is chosen, focus on symptomatic support, such as control of electrolyte and fluid status, prevention of severe anemia by use of erythropoietin, attention to the calcium phosphate balance so as to prevent pruritus, are rational. Very importantly, conservative care should focus on multidisciplinary palliative care for the patient and next of kin in the end-of-life phase $[19,22]$.

\section{Dialysis Prescription}

If the decision to start dialysis is taken, the question of optimal treatment prescription arises. In general, elderly patients are prescribed shorter hemodialysis (HD) treatment time, which is likely due to their lower body mass and urea distribution volume. Consequently, in the DOPPS study, Kt/V was not different between elderly and younger patients [2]. However, there are other reasons why shorter dialysis times may not be warranted in dialysis patients. Despite the generally lower interdialytic weight gain and ultrafiltration rates, dialysis-induced hypotension is more frequent in elderly patients [28]. This may compromise cerebral perfusion and result in deterioration of cognitive function [29]. As frail patients are more subject to loss of homeostasis [11], the question arises whether elderly patients would not benefit from prolonged and/or more frequent dialysis sessions, as compared to dialysis sessions which are reduced in time [30]. However, although in younger patients, nocturnal HD was associated with an improvement in cognitive function [31], no data are present on extended dialysis therapy in the elderly. Elderly patients may often not be willing to enter an extended dialysis program for which extra visits to the dialysis center are needed [32]. Therefore, a home dialysis program focused on the elderly, with dedicated support from home dialysis nurses, needs to be to be developed if extended HD is to be implemented. A recent study showed that such a program was feasible in elderly dialysis patients [33].

Many elderly HD patients are treated with central venous catheters. However, observational data has shown that also in the elderly, the use of central venous catheters is associated with significantly increased mortality [34]. Therefore, in our opinion, arteriovenous fistulae are preferable for vascular access in the elderly, in concordance with current guidelines $[35,36]$.

Given the absence of the large fluctuations associated with HD treatment, peritoneal dialysis (PD) would also appear to be a good option in the treatment of the elderly ESRD patient. However, both in the USA as well as in Europe, $\mathrm{PD}$ appears to be prescribed less often in elderly as compared to younger patients [37-39]. A potential disadvantage of $\mathrm{PD}$ is that elderly patients with visual or motoric problems may not be able to perform the exchanges themselves and are dependent upon family members or health professionals. The expected inability to perform exchanges was indeed a major reason not to start PD in the NECOSAD study [40]. Thus, an assisted PD program in the elderly, which should be well organized in close col- 
laboration with next of kin and other stakeholders, should remove an important barrier for prescription of PD in the elderly [41]. As for outcome, a US report suggests a higher mortality rate in elderly diabetic females [42], whereas in the EDTA registry PD was associated with a survival benefit in the elderly, except for diabetic females in which PD was also associated with increased mortality [38].

Few reports have compared the effects of HD and PD on functional status. In the report by Jassal et al. [14], a surprisingly high percentage of patients (44\%) were started on PD. This may be related to the predialysis care given to the large majority of patients (90\%). No difference in the course of functional status was observed between patients treated with PD or HD.

Thus, all available dialysis therapies appear feasible in the elderly, but need specific care and dedication for this patient group. As all data are observational and subject to various forms of bias, the potential benefits and disadvantages of current treatment modalities should be weighted on an individual basis. Of course, treatment should not focus on the prescription of a dialysis therapy alone, but should be based on a multidimensional approach of the elderly patient by a multidisciplinary team, as holds true for all dialysis patients. Furthermore, efforts focusing on rehabilitation and social support are very important in this group $[14,43]$. In a selected group of elderly patients, renal transplantation is feasible [44], but falls beyond the scope of this paper.

The time of referral to nephrological care appears to be an important predictor of outcome, also in elderly patients. In patients above 70 years of age, those who were referred to a nephrologist early had a far better 1-year survival as compared to patients who were referred late [45]. Although the latter group might have started dialysis because of a rapid decline in functional status which also influenced prognosis, early timely referral appears beneficial in elderly patients based on these observational data. Apart from the possible beneficial effect on outcome, early referral also provides time to discuss the best treatment pathway for the elderly in the shared decision process, regardless of whether a conservative approach or dialysis therapy is chosen. Moreover, early referral may also be beneficial in the elderly so as to prevent further deterioration in renal function in patients with chronic renal failure, as well as to maintain adequate control of the secondary complications [46].

\section{Conclusion}

Providing adequate care for the growing elderly ESRD population is challenging. An adequate shared decisions process, with a deliberate choice for conservative therapy or one of the forms of renal replacement, is of key importance in this population. Regardless of the treatment choice, a multidisciplinary and multidimensional approach in the care of these patients is strongly needed. Both life expectancy and life quality should be taken into account.

\section{References}

1 Kramer A, Stel V, Zoccali C, Heaf J, Ansell D, Grönhagen-Riska C, Leivestad T, Simpson K, Pálsson R, Postorino M, Jager K, ERAEDTA Registry: An update on renal replacement therapy in Europe: ERA-EDTA Registry data from 1997 to 2006. Nephrol Dial Transplant 2009;24:3557-3566.

-2 DOPPS Canaud B, Long T, Tentori F, Akiba T, Karaboyas A, Gillespie B, Akizawa T, Pisoni RL, Bommer J, Port FK: Clinical practices and outcomes in elderly hemodialysis patients: results from the Dialysis Outcomes and Practice Patterns Study (DOPPS). Clin J Am Soc Nephrol 2011;6:1651-1662.

-3 Kurella M, Covinsky KE, Collins AJ, Chertow GM: Octogenarians and nonagenarians starting dialysis in the United States. Ann Intern Med 2007;146:177-183.
4 Couchoud C, Labeeuw M, Moranne O, Allot V, Esnault V, Frimat L, Stengel B: French Renal Epidemiology and Information Network (REIN) registry: a clinical score to predict 6-month prognosis in elderly patients starting dialysis for end-stage renal disease. Nephrol Dial Transplant 2009;24:1553-1561.

-5 Jassal SV, Watson D: Dialysis in late life: benefit or burden. Clin J Am Soc Nephrol 2009; 4:2008-2012.

6 United States Renal Data System 2010: Patient characteristics. Annual data report: atlas of chronic kidney disease and end-stage renal disease in the United States. Am J Kidney Dis 2011;57(suppl 1):e267-e276.

7 Chandna SM, Schulz J, Lawrence C, et al: Is there a rationale for rationing chronic dialysis? A hospital based cohort study of factors affecting survival and morbidity. BMJ 1999; 318:217-223.
8 Cohen LM, Ruthazer R, Moss AH, Germain MJ: Predicting six-month mortality for patients who are on maintenance hemodialysis. Clin J Am Soc Nephrol 2010;5:72-79.

-9 Kurella Tamura M, O’Hare AM, McCulloch CE, Johansen KL: Signs and symptoms associated with earlier dialysis initiation in nursing home residents. Am J Kidney Dis 2010;56:1117-1126.

10 Cooper BA, Branley P, Bulfone L, Collins JF, Craig JC, Fraenkel MB, Harris A, Johnson DW, Kesselhut J, Li JJ, Luxton G, Pilmore A, Tiller DJ, Harris DC, Pollock CA, et al: A randomized, controlled trial of early versus late initiation of dialysis. N Engl J Med 2010; 363:606-619.

- 11 Fried LP, Tangen CM, Walston J, Newman $A B$, Hirsch C, Gottdiener J: Frailty in older adults: evidence for a phenotype. J Gerontol A Biol Sci Med Sci 2001;56:M146-M156. 
12 Johansen KL, Chertow GM, Jin C, Kutner NG: Significance of frailty among dialysis patients. J Am Soc Nephrol 2007; 18:2960-2967.

13 Kurella M, Chertow GM, Luan J, Yaffe K: Cognitive impairment in chronic kidney disease. J Am Geriatr Soc 2004;52:1863-1869.

14 Jassal SV, Chiu E, Hladunewich M: Loss of independence in patients starting dialysis at 80 years of age or older. N Engl J Med 2009; 361:1612-1613.

-15 Kurella Tamura M, Covinsky KE, Chertow GM, Yaffe K, Landefeld CS, McCulloch CE: Functional status of elderly adults before and after initiation of dialysis. N Engl J Med 2009;361:1539-1547.

16 Murtagh FE, Addington-Hall JM, Higginson IJ: End-stage renal disease: a new trajectory of functional decline in the last year of life. J Am Geriatr Soc 2011;59:304-308.

- 17 Fassett RG, Robertson IK, Mace R, Youl L, Challenor S, Bull R: Palliative care in endstage kidney disease. Nephrology (Carlton) 2011;16:4-12.

- 18 Kurella Tamura M, Cohen LM: Should there be an expanded role for palliative care in end-stage renal disease? Curr Opin Nephrol Hypertens 2010;19:556-560.

19 Burns A, Davenport A: Maximum conservative management for patients with chronic kidney disease stage 5. Hemodial Int 2010; $14:$ S32-S37.

20 Kurella Tamura M: Incidence, management, and outcomes of end-stage renal disease in the elderly. Curr Opin Nephrol Hypertens 2009;18:252-257.

21 Joly D, Anglicheau D, Alberti C, et al: Octogenarians reaching end-stage renal disease: cohort study of decision-making and clinical outcomes. J Am Soc Nephrol 2003; 14:10121021.

-22 Chandna SM, Da Silva-Gane M, Marshall C, Warwicker P, Greenwood RN, Farrington K: Survival of elderly patients with stage 5 CKD: comparison of conservative management and renal replacement therapy. Nephrol Dial Transplant 2011;26:1608-1614.

-23 Murtagh FE, Marsh JE, Donohoe P, Ekbal NJ, Sheerin NS, Harris FE: Dialysis or not? A comparative survival study of patients over 75 years with chronic kidney disease stage 5 . Nephrol Dial Transplant 2007;22:1955-1962.

-24 Carson RC, Juszczak M, Davenport A, Burns A: Is maximum conservative management an equivalent treatment option to dialysis for elderly patients with significant comorbid disease? Clin J Am Soc Nephrol 2009;4:16111619.
25 Burns A, Davenport A: Functional status of elderly adults receiving dialysis. N Engl J Med 2010;362:468-469.

26 Galla JH: Clinical practice guideline on shared decision-making in the appropriate initiation of and withdrawal from dialysis. J Am Soc Nephrol 2000;11:1340-1342.

27 Moss AH: Revised dialysis clinical practice guideline promotes more informed decisionmaking. Clin J Am Soc Nephrol 2010;5: 2380-2383.

28 Tislér A, Akócsi K, Hárshegyi I, Varga G, Ferenczi S, Grosz M, Kulcsár I, Löcsey L, Sámik J, Solt I, Szegedi J, Tóth E, Wágner G, Kiss I: Comparison of dialysis and clinical characteristics of patients with frequent and occasional hemodialysis associated hypotension. Kidney Blood Press Res 2002;25:97-102.

29 Stefanidis I, Bach R, Mertens PR, Liakopoulos V, Liapi G, Mann H, Heintz B: Influence of hemodialysis on the mean blood flow velocity in the middle cerebral artery. Clin Nephrol 2005;64:129-137.

30 Cornelis T, Kotanko P, Goffin E, Kooman JP, van der Sande FM, Chan CT: May intensive hemodialysis be an option to prevent loss of functionality in the elderly ESRD patient? Semin Dial, in press.

31 Jassal SV, Devins GM, Chan CT, Bozanovic $\mathrm{R}$, Rourke S: Improvements in cognition in patients converting from thrice weekly hemodialysis to nocturnal hemodialysis: a longitudinal pilot study. Kidney Int 2006;70 956-962.

32 Lacson E Jr, Wong W, Lester K, et al: Outcomes associated with in-center nocturnal hemodialysis from a large multicenter program. Clin J Am Soc Nephrol 2010;5:220226.

33 Derrett S, Darmody M, Williams S, Ruther ford M, Schollum J, Walker R: Older peoples' satisfaction with home-based dialysis. Nephrology 2010;15:464-470.

34 Ocak G, Halbesma N, le Cessie S, Hoogeveen EK, van Dijk S, Kooman J, Dekker FW, Krediet RT, Boeschoten EW, Verduijn M: Haemodialysis catheters increase mortality as compared to arteriovenous accesses especially in elderly patients. Nephrol Dial Transplant 2011;26:2611-2617.

35 NKF-KDOQI clinical practice guidelines for hemodialysis adequacy, update 2006. Am J Kidney Dis 2006;48(suppl 1):S2-S90.
36 Tordoir J, Canaud B, Haage P, Konner K, Basci A, Fouque D, Kooman J, Martin-Malo A, Pedrini L, Pizzarelli F, Tattersall J, Vennegoor M, Wanner C, ter Wee $\mathrm{P}$, Vanholder R: EBPG on vascular access. Nephrol Dial Transplant 2007;22(suppl 2):ii88-iil17.

- 37 Buemi M, Lacquaniti A, Bolignano D, Donato V, Fazio MR, Campo S, Coppolino G, Sturiale A: Dialysis and the elderly: an underestimated problem. Kidney Blood Press Rev 2008;31:330-336.

38 van de Luijtgaarden MW, Noordzij M, Stel VS, Ravani P, Jarraya F, Collart F, Schön S, Leivestad T, Puttinger $\mathrm{H}$, Wanner $\mathrm{C}$, Jager $\mathrm{KJ}$ : Effects of comorbid and demographic factors on dialysis modality choice and related patient survival in Europe. Nephrol Dial Transplant 2011;26:2940-2947.

39 Stack AG: Determinants of modality selection among incident US dialysis patients: results from a national study. J Am Soc Nephrol 2002;13:1279-1287.

-40 Jager KJ, Korevaar JC, Dekker FW, Krediet RT, Boeschoten EW, Netherlands Cooperative Study on the Adequacy of Dialysis (NECOSAD) Study Group: The effect of contraindications and patient preference on dialysis modality selection in ESRD patients in The Netherlands. Am J Kidney Dis 2004;43: 891-899.

41 Povlsen JV, Ivarsen P: Assisted automated peritoneal dialysis for the functionally dependent and elderly patient. Perit Dial Int 2005;25(suppl 3):S60-S63.

42 Vonesh EF, Snyder JJ, Foley RN, Collins AJ: The differential impact of risk factors on mortality in hemodialysis and peritoneal dialysis. Kidney Int 2004;66:2389-2401.

43 Jassal SV, Watson D: Doc, don't procrastinate... rehabilitate, palliate, and advocate. Am J Kidney Dis 2010;55:209-212.

- 44 Heldal K, Hartmann A, Grootendorst DC, de Jager DJ, Leivestad T, Foss A, Midtvedt K: Benefit of kidney transplantation beyond 70 years of age. Nephrol Dial Transplant 2010; 25:1680-1687.

-45 de Jager DJ, Voormolen N, Krediet RT, Dekker FW, Boeschoten EW, Grootendorst DC, NECOSAD Study Group: Association between time of referral and survival in the first year of dialysis in diabetics and the elderly. Nephrol Dial Transplant 2011;26:652658

-46 Levin A: Consequences of late referral on patient outcomes. Nephrol Dial Transplant 2000;15(suppl 3):8-13. 